\title{
Heritage tourism: reconciling urban conservation and tourism
}

\author{
W. M. Sudi \\ Department of Building and Civil Engineering, \\ Technical University of Mombasa, Kenya
}

\begin{abstract}
As a result of urbanisation and globalisation, many ancient and new settlements in the world have lost the features which define their identity. In the east African Coast, such features are fast disappearing. This erosion of the architectural heritage is closely linked with the loss of a socio-cultural identity and consequently resulting in the deterioration of the quality of urban life. Various means have been tried to try to improve this historic built environment, with the symbiosis of both tourism and heritage places becoming a major objective in the management and planning of historic areas.

With sustainable settlement being a global concern, and within the context of the historic urban areas of Lamu and Mombasa Old Towns, this paper explores the current conflicts among the ideas of urban conservation, heritage and tourism, arguing that the most sustainable approach to management of historical areas is the one based on community and culture-led agenda.

In terms of the sustainability of heritage places, it is viewed in this study that managing tourism can have substantial inherent potential to underpin sustainable development and urban conservation. It will be concluded that, tourism can have positive attributes for conservation and development in heritage places.

Keywords: Swahili architecture, architectural heritage, conservation, tourism, sustainable development.
\end{abstract}

\section{Introduction}

Mombasa and Lamu were among more than thirty independent city-states, which flourished along the East African coast at the height of the Swahili civilisation, from the thirteenth through the fifteenth centuries (Siravo and Pulver [1]). For 
thousands of years, the area stretching from south of Somalia to north of Mozambique has been part of a great circle of trade that has taken place in the Indian Ocean (Sudi [2]). From as far as Sumatra, India and the Arabian Peninsula traders brought porcelain from China, glass beads from India, and clothes from Egypt and Somalia (Figure 1). Each year, they returned east with the summer monsoons carrying cargo of ivory, iron, gold, timber and slaves. Iron ore was mined in Tanzania while Mombasa and Lamu were famous for ivory for mangroves respectively.

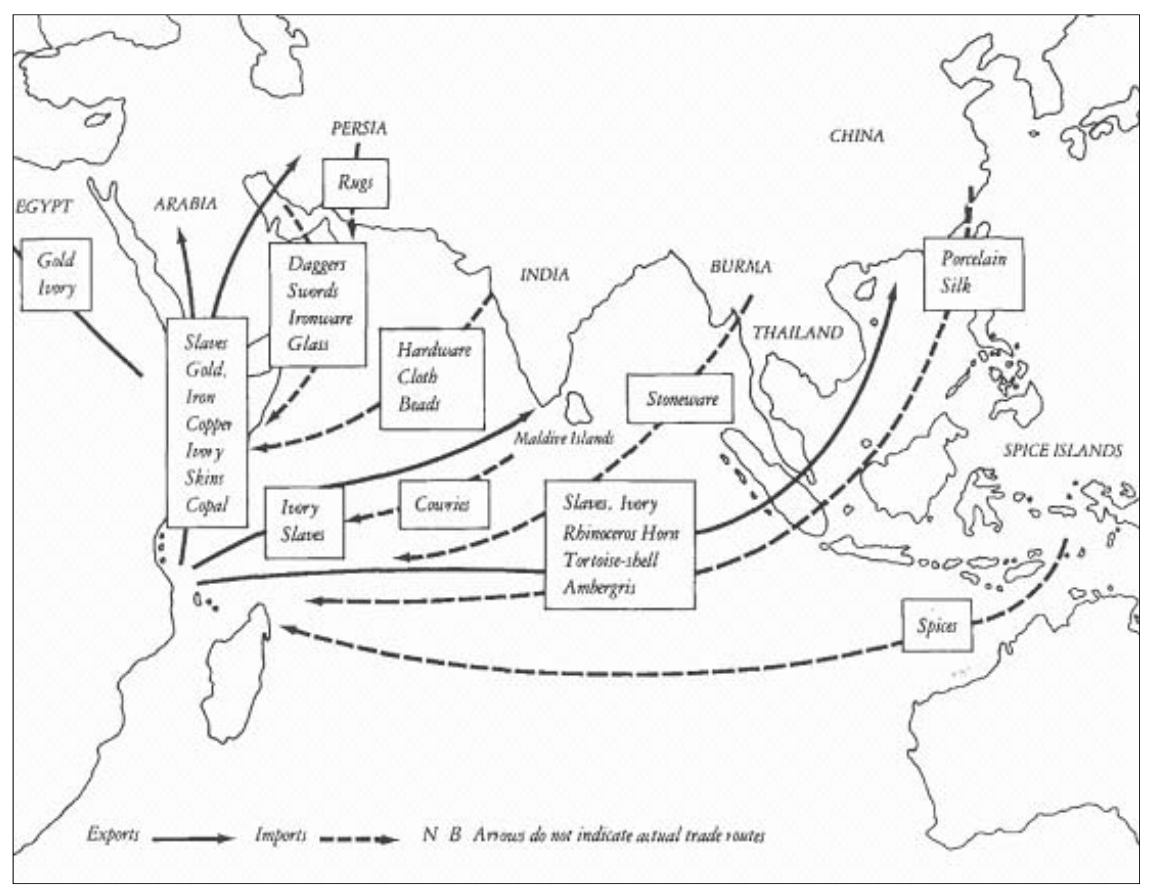

Figure 1: $\quad$ Map of the Indian Ocean maritime trade.

In the course of this continuous maritime contacts many people from the Arabian Peninsula, the Indian sub-continent and to some extent Europe, migrated to the East African Coast, mingled and intermarried with the local ethnic groups. These contacts also resulted in the introduction of not only new religions of which Islam was predominant but also gave birth to a common culture and language, Swahili, from the Arab word Sahil for coast. The settlements that grew up along the coastal region were one of the direct results and the most visible aspect of this unique culture.

Today most of these settlements have either disappeared and exist in the form of ruins or have transformed into modern towns. For instance Gede, a major trading centre in the Kenyan Coast during that period was abandoned in the late nineteenth century and is now in ruins (Figure 2) while Mzizima has transformed 
into the modern city of Dar-es-Salaam, the capital City of Tanzania. Amid pressures for change, Mombasa (Figure 3) and Lamu in Kenya and Zanzibar and Bagamoyo in Tanzania, however, still maintain some character that can be identified with the Swahili Culture. It was in recognition to this threat that the Lamu and Mombasa old towns are now gazetted as protected historic areas with conservation plans to guide their respective developments.

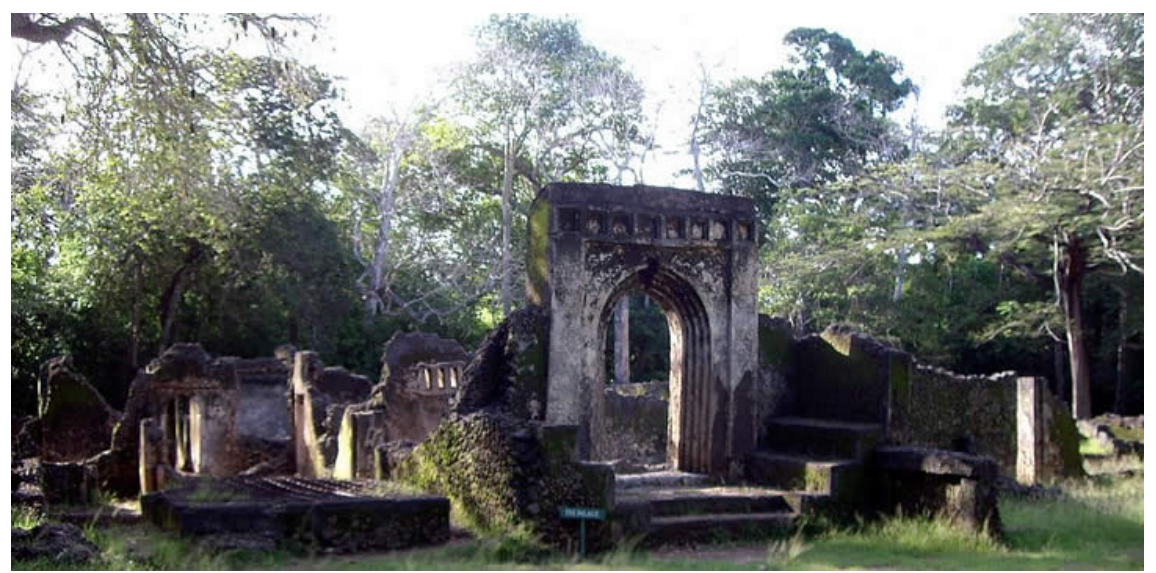

Figure 2: $\quad$ Gede ruins.

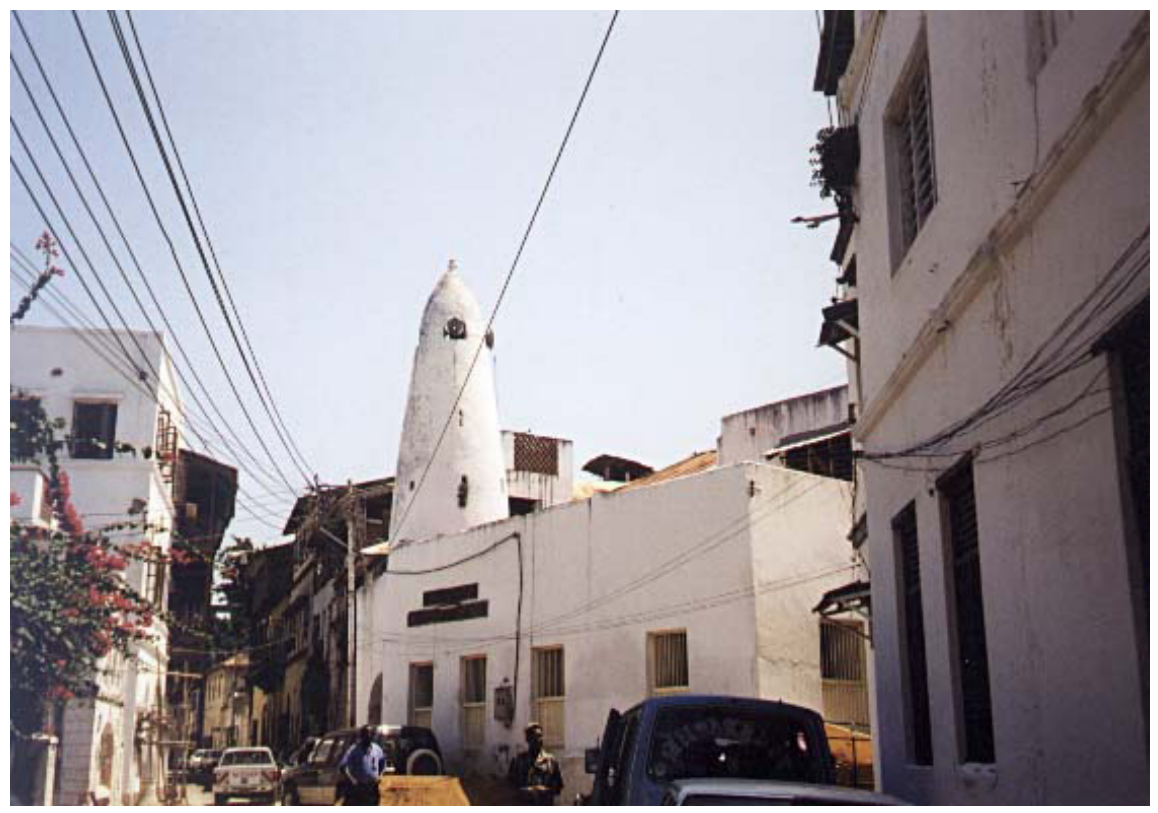

Figure 3: $\quad$ Section of Mombasa Old Town. 


\section{Research objectives}

Globalizing forces inherent in the shift from production to consumption are influencing changes in the built environment and in their local cultures. This is most acute in places of heritage value where the local culture with its built heritage is being transformed into a product for tourist consumption. The global scale of tourism and its accrued uniformity are increasingly evident, particularly the proliferation of standardised hotel architecture, restaurant chains, and street furniture. Similarly, local cultures are losing their local identities as global "cultural industries" dominate (Oncu and Weyland [3]). With the emergence of a greater number of destinations competing for unique tourist experiences, traditional historic places are undergoing a redefinition and reinterpretation of their cultural heritage in order to be competitive and attractive. By doing this, however, heritage places are responding to the commercial forces of consumer demand, and in many cases conservation and cultural values are being compromised.

Within the context of the historic urban areas of Lamu and Mombasa Old Towns, this research study explores the sustainability of the Swahili architecture. It provides a critical analysis of the current conflicts among the ideas of urban conservation, heritage and tourism, presenting the idea of sustainability as an overarching framework for managing tourism in heritage places based on the balance between socio cultural needs, economic gain, and the protection of the heritage resource.

\section{Research methodology}

The research is mainly through desktop analysis with some references to the conservation initiatives in the historic areas of Lamu and Mombasa Old Towns. This research will begin by highlighting the various concepts associated with heritage places that are considered in any sustainable planning for such areas. The first concept is building preservation and conservation in which the primary concern is protecting the built and cultural heritage. The second concept revolves around the exploitative nature of heritage tourism in which commercial gain has created an imbalance in conservation and cultural values. The third and final concept is that of sustainable tourism. It is the third concept that this paper will highlight, arguing for an alternative tourism that will contribute to both conservation and development objectives, as well as safeguard social equity and cultural values.

\section{Evolution of concepts of heritage protection}

\subsection{From building preservation to urban conservation}

The first concept is building preservation and conservation in which the primary concern is protecting the built and cultural heritage. A brief introduction to the historical roots of conservation will highlight many of the continuing debates of 
modern conservation approaches, especially issues of selectivity and authenticity. Jokilehto's [4] extensive overview of the history and theory of architectural conservation include the origins of the interest in conservation within the European context where it began. In these initial stages therefore, the approach toward conservation was that of repair and restoration, influenced by a small and wealthy intellectual élite.

With time however, changing fashions influenced approaches to the conservation and restoration of historic objects and places. Classicism at the end of the eighteenth century encouraged the idea of mimesis (the imitation of models or objects in order to reach the closest possible resemblance), which was challenged in the age of Romanticism. This new approach of "stylish restoration" was founded on respect for the original style not any more for purely aesthetic reasons but due to the building's significance as a representation of achievements in the nation's history (Jokilehto [4]). Restoration of a historic building came to be seen as a scientific activity that aimed at stylistic unity as an illustration of an ideal. In Kenya the restoration of Fort Jesus in Mombasa Old Town, and the Lamu Fort in Lamu Old Town is a manifestation of this principle.

The conception of stylistic restoration during the age of Romanticism raised issues of "authentic restoration" and "style selectivity" that faced increasing criticism in the second half of the nineteenth century and saw the rise of an "antirestoration movement" and modern conservation. Two schools of thought developed on the principles of restoration, as Jokilehto [4] explains: the first wanted to preserve the remains even if mutilated; the second group referred to go ahead with a "careful restoration”. This principle is also widely applied in Kenya with the restoration of monuments like the Jumba ruins in Mtwapa and Gedi ruins being good examples.

The anti-restoration movement, instigated by John Ruskin in the mid $19^{\text {th }}$ Century, was directed at the fashion of stylistic restoration, criticising restoration architects for the destruction of the historical authenticity of the buildings and fighting for their protection, conservation, and maintenance. Ruskin argued that authenticity meant a retained building should be restored to its original state and use where possible and that its age gave it historical value and interest (Violettele-Duc [5]). William Morris, founder of the Society for the Protection of Ancient Buildings (SPAB), reflects the beginning of the modern approach to conservation that quickly spread internationally.

Since the 1960s, shifts in the approach toward conservation widened the object of attention to ensembles and areas, as opposed to the previous approach, focusing on buildings or their remnants as monuments. This is the guiding concept for urban conservation in Kenya where sections of historic areas such as Lamu and Mombasa Old Towns are identified and safeguarded. The presence of an overall architectural quality or historical association would define such designated areas, often denoting a significant historical and social relationship to the rest of the town.

From the above analysis therefore, urban conservation as we know it today appear to have three interrelated objectives; physical, spatial, and social. 
1. Physically, it is linked to building preservation and the type of new development to ensure that a town's past, its present, and its future combine to create a recognisable unit, so that its growth can be seen and felt to be continuous. This involves seeking to improve old environments and bring them into modern use by adapting the townscape, but as Larkham [6] suggests, this is hard to achieve without wasting some of the investment of previous societies.

2. Spatially, it is viewing the townscape as a holistic entity, with its relationships between spaces and their use, as well as circulation and traffic.

3. The third objective, and most neglected, is social, which concerns the users, local community, and the urban population.

Although the social dimension is the most difficult to define, it is the most important, as continuity in urban conservation can be achieved only through the continuation of that urban life.

\subsection{The shift to the heritage approach}

Providing "the link between the preservation of the past for its intrinsic value, and as a resource for the modern community as a commercial activity", heritage appears to be the modern phase of conservation (Ashworth and Tunbridge [7]). This approach focuses upon the relics of history as a product, whereas preservation and conservation have no such direct implication and focus on the artefact or area itself. This distinction has consequences in the approaches to historic city management.

Ashworth and Turnbridge [8] argue that heritage is the product of a "commodification" process in which selection is central: heritage conservation is creation and not preservation of what already exists. The nature of the final product (as heritage) is not determined by the resources endowment, nor can it reflect any supposedly accurate factual record of the past. Schouten [9] adds that heritage is a product and, as a product, it is subject to difference in validation and interpretation as the historical process itself.

Heritage changes over time in the way it is presented and also in the ways in which the public reacts to its presentation. Hence, there is a tendency to change the past to suit changing requirements; relics can be adapted, added to, copied, and interpreted, all of which idealise the past.

Since heritage cannot logically exist without a consumer, then, in effect, the consumer defines heritage. Then, the perceived problem of authenticity is largely irrelevant in heritage planning, because the consumer authenticates the resource.

\subsection{The tourism-heritage relationship}

The second concept revolves around the exploitative nature of heritage tourism in which commercial gain has created an imbalance in conservation and cultural values. With the conservation of Mombasa and Lamu Old Towns, it appears the need to manage the urban historic areas, as long practised in the industrialised west has now gained considerable attention in developing African countries like Kenya. Party from pride in or need to preserve the nation's heritage, this has been 
mainly motivated by the potential contribution this cultural asset to development through tourism (Sudi [11]. As with any economic activity, however, tourism makes use of resources and produces an environmental impact that amounts to exploitation if the quantity and quality of those resources are degraded.

Newby [12] identifies a complex relationship between heritage and tourism in which culture evolves from being a shared entity, to being exploited, and in extreme cases created. When culture is shared, tourism and heritage coexist so that tourism revenues can be used to sustain and conserve environments of heritage value. However, when culture is exploited or created, there is an explicit domination of commercial values over conservation values as tourism becomes central to the local economy. In the cases of Lamu and Mombasa Old Towns, the cultural heritage has become a consumer product susceptible to a selection process restricted by the choice, fashion, and taste of international organisations involved in the marketing of the heritage product, and the consumers. Selectivity in tourism has generated cultural and economic problems, of which the latter has the greatest impact on the conservation of the built heritage. Commercial pressures exerted through the tourism industry, particularly in Lamu, have led to public investment in conservation being directed disproportionately to support the tourism economy.

Moreover, tourism activities have resulted in land use selectivity. Tourist activities and the growing number of tourists induce spatial transformation processes. Changes in the morphology of the place, in the physical structures, in the functional patterns, and in the use of public space all contribute to this transformation process. Jansen-Verbeke [13] reveals that different tourist activities have a physical impact on artefacts in the urban environment. Tourists visiting historical cities are attracted by the spatial concentration of historic buildings as a setting for sight-seeing and the range of opportunities for cultural activities such as visiting museums. The number of attractions and the actual dispersion of interesting artefacts in the historic city explain to a large extent the way in which the tourist activity is evolving in time and space, causing over crowdedness, traffic congestion, shortage of parking, biased range in retail trades, rising prices, and intrusion in the private domain, ultimately leading to conservation bias (Jansen-Verbeke [13]).

Tourists may be strongly attracted to the conserved relics of the past, but tourists also require modern support facilities. Those functions that support the tourist activity may provide a use and justification for parts of the historic city, but simultaneously they attract less-welcome land use demands, such as hotels and infrastructure needed to cope with the high demands of tourists (Ashworth and Tunbridge [8]). The progressive domination of tourist service functions leads to functional conversion, particularly from retail to food service provisions, and the expansion of the tourist area into surrounding craft and residential areas.

Moreover, a particular form of tourism referred to as "enclave tourism" occurs where the type and location of facilities are not oriented toward the local community (Healy [14]). Money generated from these enclaves generally has little effect on the local economy or even the host country, especially if foreign interests own them. "Heritage shopping" is one example of a district created 
specifically to serve the needs of recreation and particularly the needs of the tourists. Although from a conservation perspective the historic buildings are being reused, two problems arise.

Firstly, more attention is paid to the conservation of those areas of the historic city that are intensively used by tourism, resulting in land use selectivity. Secondly, this leads to upward inflationary pressure on local economies. Prices of land and property, as well as the goods that are being sold, are neither affordable nor responsive to local needs. This "export” orientation ultimately leads to higher rent prices, distorting the character of the area and creating an "outsider" zone in the heart of the historic city. Moreover, if land is sold as freehold to the developers, it means loss of sovereignty for the locals, translated into loss of control in decision making, as well as loss of benefits.

Tourism also has economic impacts on local populations of historic cities. The local economy may be disturbed through the introduction of tourist earnings making some locals richer than others. High inflation from tourism pushes prices up beyond the reach of the local community, restricting resources to foreign investors and tourists that could cause resentment among locals. This results in inevitable economic leakages, compounded by the international organisational arrangement of tourism. The majority of tourists originate from the developed countries, and consequently their tour, travel, and accommodation needs are largely coordinated by firms based in these countries. As a result, a large percentage of expenditure is not made at the destination end. Data from the Kenya Tourism Development Authority indicates that the proportion of a total inclusive tour price that is retained locally drops to only 22 to 25 percent, if both the airline and hotel are foreign-owned.

\section{Can heritage tourism be sustainable?}

The third and final concept is that of sustainable tourism. The realisation that mass tourism in many cases is destructive of culture, the environment, and the built resources has contributed to the development of alternative forms of tourism. Viewed as a form of alternative tourism, the concept of sustainable tourism has been motivated by the growth in environmental awareness among many people and the recognition among conservationists that tourism is one method of capturing conservation values for conservation purposes.

Sustainable tourism is rooted in sustainable development, in the sense that if tourism is to contribute to sustainable development, it must be economically viable, environmentally sensitive, and culturally appropriate. Two schools of thought have developed views on sustainable tourism. The first argument reflects the functional approach of analysing tourism and its impact on the tourist destination as a cultural resource, whereas the second is referred to as the political economy approach, which takes the view that in order to minimise the worst examples of exploitation, host countries and populations need to seek public ownership of the tourist industry and direct marketing of the product (Lea [10]). Wall [15] supports the first approach and is skeptical when he argues that 
"few see tourism as a pollution-free industry which is environmentally benign, although many would accept that it is in the long-term interests of the tourist industry to assure the longevity of the resources on which it depends. But this is easier said than done, for tourism exhibits many of the attributes of common property resources, with most money being spent on transportation, accommodation, and food and beverages, and relatively little being directed to the maintenance of the natural and cultural heritage resources on which tourism ultimately depends.”

Nevertheless, proponents of sustainable tourism believe that if development is founded on small-scale, locally owned activities, tourism can fulfil a nonconsumptive use of resources, which appears to have the potential to serve both conservation and local development roles as well (Furze et al. [16]). In this case, the benefits are threefold.

Firstly, there will be less need for financial investment in infrastructure and superstructure facilities compared to conventional mass tourism. Secondly, locally owned and operated businesses will not have to conform to the corporate Western identity of multinational tourism concerns and therefore can have a much higher input of local products, materials, and labour. Thirdly, the profits made should accrue locally instead of flowing back to the state or foreign organisations.

Sustainable tourism activities concerns many government ministries, so it is vital to integrate planning for sustainable tourism with national development plans in general and sector targets in particular. It is also necessary to recognise the mutually dependent interests of the public and private sectors in tourism. It is in the government's interests to create the conditions and business environment within which private local business can make a reasonable profit.

Finally, the most vital factor to ensure sustainability of tourism development is to increase local involvement. There has been a growing consensus among scholars of the importance of local involvement to ensure sustainability, as Rees [17] encapsulates,

"Sustainable development is positive socioeconomic change that does not undermine the ecological and social systems upon which community and society are dependent. Its successful implementation requires integrated planning, and social learning processes; its political viability depends on the full support of the people it affects through their governments, their social institutions, and their private activities."

There are sound reasons for local involvement other than the moral obligation to incorporate people in shaping their own destiny. In terms of the conservation of the cultural resource base, the local population's time perspective is longer than that of outside entrepreneurs concerned with early profits. The longer view is also likely to ensure that traditions and lifestyles are respected. There are also sound reasons in terms of creating local employment and reviving the local economy. The nature of involvement should take many forms, not just the provision of schools, hospitals, and social services financed from tourism but also through the replacement of alternative economic livelihoods, if the traditional is being removed from the community (Cater [18]). Such an 
involvement extends beyond economic survival, environmental conservation, and socio-cultural integrity, but it allows the community to appreciate its own resources.

\section{Conclusion}

This paper has examined the potential relationships between tourism, urban conservation, and planning within the sustainability discourse. In this respect four objectives have been identified:

- The need for long-term planning,

- The need to protect the cultural heritage as a natural resource that if overexploited will be degraded,

- The acceptance of change and development to ensure continuity, and

- The need to consider equitable access to heritage resources by the local community and visitors.

In terms of the sustainability of heritage places, it is viewed in this study that managing tourism can have substantial inherent potential to underpin sustainable development and urban conservation.

1. First, tourism can yield economic development at the local, regional, and national levels, creating jobs and bringing in much-needed foreign income. However, mechanisms for ensuring equitable access to social and economic resources and their distribution among all social groups of the local community require careful management. One area of sustainability that has received markedly less attention is that of financial resource mechanisms. Revenues generated from tourism should feed back into the local community through mechanisms of cross-subsidisation such as revolving trusts to refurbish and reclaim buildings or enforced entrance fees to tourist attractions. Such initiatives have been applied in both conservation areas of Lamu and Mombasa Old Towns. Revenues have been used to improve local incomes, saving and enhancing whole areas of towns.

2. Second, tourism also has the potential to create more demand for conserving buildings including less valued monuments and overlooked traditional environments.

3. Third, tourism can create uses for redundant buildings, which if carefully managed, can contribute to preservation.

4. Fourth, tourism can also increase an appreciation for the historic environment, contributing to greater local and cross-cultural understanding.

In conclusion, tourism can have positive attributes for conservation and development in heritage places. For planners, the principal goal should be to create a strategy for minimising the adverse impacts and maximising gains from tourism. This would have to include the management of the cultural resource and the quality of new development, the uses and activities the built environment sustains, and the integration of both these factors with the socio-cultural needs of the local community. 


\section{References}

[1] Siravo, F. and Pulver, A. (1986): Planning Lamu: Conservation of an East African Sea Port. National Museums of Kenya. Nairobi

[2] Sudi, W. M. (1994): 'Urban Conservation in Kenya' in Centre for Built Environment Proceedings of an International workshop on Urban Conservation. Calcutta.

[3] Oncu, A. and P. Weyland. (1997): Struggles over Lebenstraum and social identities in globalising cities. In Space, culture and power: New identities in globalising cities, A. Oncu and P. Weyland, eds. London: Zed Books.

[4] Jokilehto, J. (1999): A history of architectural conservation. Oxford, UK: Butterworth-Heinemann.

[5] Violette-le-Duc, E. E. (1987): Violette-le-Duc, E. E. 1918-1987 Lectures on Architecture, Vols. 1-2, translated by B. Bucknall. New York and London: Constable

[6] Larkham, P. J. (1996): Conservation and the City. London: Routledge

[7] Ashworth, G. J., and J. E. Tunbridge. (1990): The tourist-historic city. London: Belhaven.

[8] Ashworth, G. J., and J. E. Tunbridge. (1992): Heritage and tourism: An argument, two problems and three solutions. In Spatial implications of tourism, C.A.M. Fleischer van Roojen, ed. Groningen, the Netherlands: Geo Pers.

[9] Schouten, Frans J. (1995): Heritage as historical reality. In Heritage, tourism and society, D. T. Herbert, ed. London: Mansell.

[10] Lea, J. (1988): Tourism and development in the third world. New York: Routledge.

[11] Sudi, W. M. (2004): Public Participation in the Conservation Process. Unpublished PhD thesis at the University of Lincoln, UK

[12] Newby, Peter T. (1994): Tourism-Support or threat to heritage. In Building a new heritage: Tourism, culture, and identity, G. J. Ashworth and P. J. Larkham, eds. London: Routledge.

[13] Jansen-Verbeke, M. (1997): "Urban tourism: Managing resources and visitors". In Tourism, development and Growth, S. Wahab and J. J. Pigram, eds. London: Routledge.

[14] Healy, R. (1992): “The role of tourism in sustainable development”. Paper presented at the IVth World Parks Congress on National Parks and Protected Areas, February 10-21, Caracas, Venezuela.

[15] Wall, G. (1997): "Sustainable tourism-Unsustainable development". In Tourism, development and growth, S. Wahab and J. J. Pigram, eds. London: Routledge.

[16] Furze, Brian, Terry de Lacy and Jim Birckhead (1996): Culture Conservation, and Biodiversity. Chichester, UK: Wiley

[17] Rees, W. E. (1989): Defining sustainable development. Center for Human Settlements research bulletin. Vancouver, Canada: Center for Human Settlements, University of British Columbia. 
1116 The Sustainable City VIII, Vol. 2

[18] Cater, E. (1994): "Ecotourism in the third world-Problems and prospects for sustainability”. In Ecotourism: A sustainable option? E. Cater and G. Lowman, eds. Chichester, UK: Wiley. 